\title{
Analisis Mutu Formulir di Unit Rekam Medis
}

\section{Analysis of Form Quality in the Medical Record Unit}

\author{
Arifatun Nisaa ${ }^{1}$ \\ Sapurni Dian Safitri ${ }^{2}$ \\ Ferdian Kurniawan ${ }^{3}$ \\ Nevi Isdha Wulan Jaya ${ }^{4}$
}

\author{
1,2,3,4)Progdi. Perekam E Informasi Kesehatan, Universitas Veteran Bangun Nusantara \\ Dengan alamat Jl. Letjend Sujono Humardani, No 1 Kampus Jombor, Kab. Sukoharjo \\ E-mail:arifatun.nisaa@gmail.com
}

\begin{abstract}
One of the tasks of the medical record unit is to create a form design that is tailored to the needs of the hospital. To make a good form design, one must pay attention to the aspects of the form and quality data characteristics. A good form design will make it easier to fill in and further data processing. The research method used is descriptive qualitative research with a case study design. While the research instrument used was the observation checklist sheet and interview guide. Research results: the title of the form has not been included on the form analyzed as an introduction and there is also no instruction. In terms of the contents of the RM01 form, it is necessary to add date of birth items, and Phone Number on the patient's identity, on the column for filling No. In RM, six columns are sufficient to fill in the six-digit medical record number. Conclusion: It is necessary to update the design on each form by adding the month / year of publication that appears on each form. The form numbering is placed after the last form code was published and then Rev-0 (if the form is new or Rev-1 if the form is revised.
\end{abstract}

Keywords: form quality management; form design analysis; form design; health information management

\begin{abstract}
Abstrak
Salah satu tugas unit rekam medis adalah membuat suatu desain formulir yang disesuaikan dengan kebutuhan di rumah sakit. Untuk membuat suatu desain formulir yang baik harus memperhatikan aspek-aspek formulir dan karakteristik data yang berkualitas. Desain formulir yang baik akan mempermudah pengisian dan pengolahan data selanjutnya. Metode penelitian yang digunakan adalah Penelitian deskriptif Kualitatif dengan Rancangan Studi Kasus. Sedangkan instrumen penelitian yang digunakan adalah lembar checklist observasi dan panduan wawancara. Hasil penelitian: judul formulir belum dicantumkan pada formulir yang dianalisis sebagai introduction serta juga tidak terdapat instruction. Dilihat dari segi isi formulir RM-01 perlu ditambahkan item TTL, dan No. HP pada identitas pasien, pada kolom untuk pengisian No. RM cukup diberikan enam kolom untuk pengisian enam digit nomor rekam medis. Kesimpulan: Perlu dilakukan pembaruan desain formulir dengan menambahkan bulan/ tahun penerbitan yang muncul pada setiap formulir. Penomoran formulir dituliskan setelah kode formulir lalu bulan terbit , kemudian keterangan Rev-0 (jika Formulir baru atau Rev-1 jika formulir di revisi)
\end{abstract}

Kata kunci: manajemen mutu formulir; analisis desain formulir, desain formulir, manajemen informasi kesehatan 


\section{Pendahuluan}

Berdasarkan Undang-Undang No. 44 tahun 2009, rumah sakit adalah institusi pelayanan kesehatan bagi masyarakat dengan karakteristik tersendiri yang dipengaruhi oleh perkembangan ilmu pengetahuan kesehatan, kemajuan teknologi dan kehidupan sosial ekonomi masyarakat yang harus tetap mampu meningkatkan pelayanan yang lebih bermutu dan terjangkau oleh masyarakat agar terwujud derajat kesehatan yang setinggi-tingginya.

Setiap sarana pelayanan kesehatan perlu adanya upaya peningkatan mutu dan sistem pelayanan kesehatan. Upaya tersebut harus disertai dengan adanya sarana penunjang yang memadai dan dukungan dari beberapa faktor yang terkait. Salah satu faktor untuk meningkatkan mutu dan sistem pelayanan di rumah sakit adalah dengan mengusahakan terciptanya manajemen pelayanan Rekam Medis Rumah Sakit yang baik (Alamsyah, 2011).

Salah satu tugas unit rekam medis adalah membuat suatu desain formulir yang disesuaikan dengan kebutuhan di rumah sakit (Cripps, H. dan Standing, C, 2011). Untuk membuat suatu desain formulir yang baik harus memperhatikan aspek-aspek formulir dan karakteristik data yang berkualitas (Tierney et al., 2013). Desain formulir yang baik akan mempermudah pengisian dan pengolahan data selanjutnya (Tola, K. et al., 2017). Selain membuat desain formulir, seorang perekam medis mampu melakukan klasifikasi dan kodefikasi penyakit, masalahmasalah yang berkaitan dengan kesehatan dan tindakan medis. Artinya bahwa seseorang profesi perekam medis harus mampu menetapkan kode penyakit dan tindakan deengan tepat sesuai klasifikasi yang diberlakukan di Indonesia yaitu ICD 10 untuk kode penyakit dan ICD 9 CM untuk kode tindakan medis (Khalifa, 2013).

\section{Metode}

Metode penelitian yang digunakan adalah Penelitian deskriptif Kualitatif dengan
Rancangan Studi Kasus. Sedangkan instrumen penelitian yang digunakan adalah lembar checklist observasi dan panduan wawancara.

\section{Hasil dan Pembahasan}

Desain formulir adalah kegiatan merancang formulir berdasarkan kebutuhan pencatatan transaksi pelayanan, kegiatan pelayanan dan penyusunan atau pembuatan laporan organisasi. Desain formulir merupakan secarik kertas yang memiliki ruang untuk diisi dan dokumen yang digunakan untuk merekam terjadinya transaksi. Dapat diartikan bahwa dengan dibuatnya desain formulir yang formatnya standar dan ada keterangan tentang isian yang dimaksud maka isi dari formulir terebut akan mudah dipahami oleh banyak orang dan mudah dalam penggunaan pengisiannya.

\section{Analisis Aspek Formulir Rekam Medis:}

a. Aspek Anatomi

1) Heading (Kepala formulir)

Kepala formulir biasanya mencakup judul formulir dan informasi tentang formulir. Judul sebuah formulir bisa terdapat pada satu dari beberapa tempat. Posisi standardnya adalah: kiri atas, tengah, kanan atas, kiri bawah atau kanan bawah. Pada file yang terlihat, judul harus berada di atas sehingga informasi kntrol yang berhubungan bisa terlihat di bagian dasar.

\section{2) Introduction (Pengantar)}

Bagian pendahuluan ini menjelaskan tujuan formulir. Tujuan di tunjukkan oleh judul. Penjelasan lebih lanjut diperlukan pernyataan yang jelas biasa dimaksukkan di dalam formulir untuk menjelaskan tujuannya.

\section{3) Intructions (Instruksi)}

Instruksi umum harus singkat dan berada pada bagian atas formullir. Jika 
diperlukan instruksi yang lebih detail, sisi balik formulir dapat digunakan namun harus ada rujukan mengenai hal ini. Instruksi tidak boleh diletakkan diantara ruang-ruang entry karena hal ini membuat foemulir terkesan berantakan dan mempersulit pengisian.

\section{4) Body (Badan)}

Bagian ini merupakan bagian formulir yang disediakan untuk kerja formulir yang sesungguhnya. Dalam menyusun data yang diminta atau informasi yang tersedia mencakup pengelompokan, pengurutan, dan penyusunan tepi ("aligning"), yang harus dipertimbangkan. Margins, spacing, rules, type, styles, dan cara pencatatan juga harus dipertimbangkan.

Margins adalah batas pinggir formulir yang tidak hanya menambah tampilan dan kegunaan formulir, tetapi juga merancang formulir secara fisik. Margin minimum bagian atas 2/16", margin bagian bawah $3 / 6^{\prime \prime}$, dan bagian sisi-sisi 3/10". Sedangkan 1/8" jika menggunakan stok kartu.

Spacing adalah ukuran area entry data. Spacing dibagi menjadi Horizontal spacing dan vertical spacing. Horizontal spacing disediakan 1/12" untuk huruf "elite", untuk huruf "pica" 1/10". Vertical spacing terdapat 6 garis vertikal setiap inci pada mesin ketik standar, elite atau pica.

Rules adalah garis vertical atau horizontal yang bisa solid (langsung), dotted (terputus-putus), atau paralel berdekatan.

Type style adalah jenis huruf yang penting dalam hal penonjolan dan keterbacaan. Untuk suatu formulir yang paling baik menggunakan sedikit jenis dan ukuran huruf. Biasanya italic dan bold digunakan untuk penekanan.

5) Close (Penutup)
Komponen utama terakhir formulir kertas adalah close atau penutup. Ini merupakan ruangan untuk tanda tangan persetujuan.

b. Aspek Fisik

1) Dalam aspek fisik berat kertas standar untuk formulir rekam medis berkisar 70-80 gram.

2) Warna dasar formulir putih atau warna muda lainnya untuk menjaga nilai kontras antara warna dasar formulir dengan warna tintanya.

3) Bentuk standar formulir adalah segi empat.

4) Ukuran standar kertas adalah A4. Jenis guruf biasanya menggunakan Times new roman

c. Aspek Isi

1) Tersedia tempat holepunch;

2) Data pasien tidak menjadi satu kesatuan;

3) Check boxs;

4) Adanya garis pemisah satu dengan yang lainnya;

5) Tercantumnya nama dan nomor rekam medis pasien;

6) Simbol dan singkatan ada dan mudah dipahami;

7) Layout tersusun dengan konsisten.

\section{Ketentuan Pengisian Formulir Rekam Medis}

Rekam medis harus dibuat segera dan dilengkapi seluruhnya setelah pasien menerima pelayanan dengan ketentuan sebagai berikut:

a. Setiap tindakan konsultasi yang dilakukan terhadap pasien, selambat-lambatnya dalam waktu $1 \times 24$ jam harus ditulis dalam lembaran rekam medis;

b. Semua pencatatan harus ditanda tangani oleh dokter atau tenaga kesehatan lainnya sesuai dengan kewenangannya dan ditulis nama terangnya serta diberi tanggal;

c. Pencatatan yang dibuat oleh mahasiswa kedokteran dan mahasiswa lainnya ditanda tangani dan menjadi tanggung jawab dokter yang merawat atau oleh dokter 
pembimbingnya;

d. Catatan yang dibuat oleh residens harus diketahui oleh dokter pembimbingnya;

e. Dokter yang merawat dapat memperbaiki kesalahan penulisan dan melakukannya pada saat itu juga serta dibubuhi paraf;

$f$. Penghapusan tulisan dengan cara apapun tidak diperbolehkan.

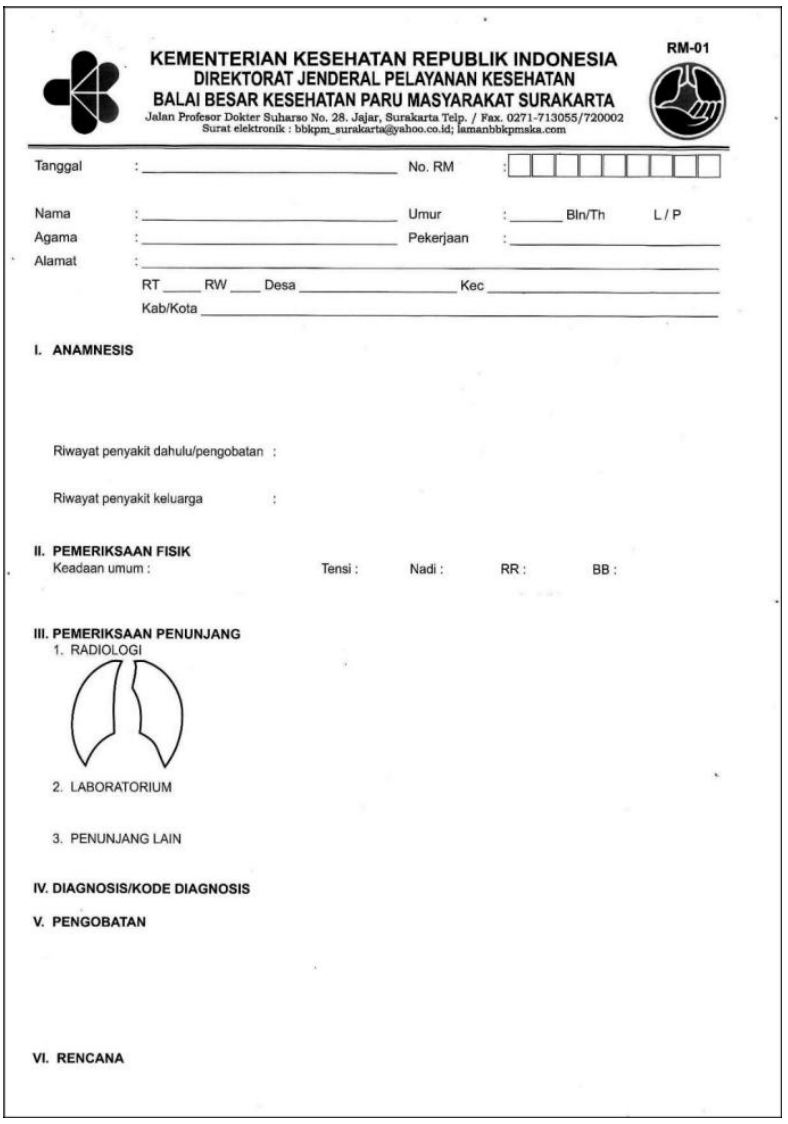

Gambar 1. Formulir / lembar anamnesis yang ada di Balai Besar Kesehatan Paru Masyarakat Surakarta

Dilihat dari segi fisik formulir RM-01 yang ada di BBKPM Surakarta sudah baik. Dilihat dari segi anatomi formulir RM-01 yang ada di BBKPM Surakarta pada heading sudah tepat yakni dengan mencantumkan identitas lengkap dari BBKPM Surakarta. Untuk nomor halaman juga sudah sesuai yakni berupa urutan angka atau alfabet, dan terletak pada sudut kanan-atas dengan tujuan memudahkan pencetak dalam menyusun material untuk dicetak dan disusun. Namun, judul formulir belum dicantumkan pada formulir sebagai introduction, seharusnya pendahuluan memuat informasi pokok yang menjelaskan tujuan dari penggunaan formulir yang bersangkutan berupa dicantumkannya judul pada setiap formulir rekam medis dengan tujuan memudahkan petugas dalam pengisian formulir dan mampu memenuhi komponen yang biasanya ada pada formulir berbasis kertas (paper based).

Pada formulir RM-01 juga tidak terdapat instruction, sehingga penulis menyarankan menambahkan instruction berupa perintah "coret yang tidak perlu" pada item umur dan jenis kelamin agar memudahkan petugas dalam pengisian. Dilihat dari segi isi formulir RM-01 perlu ditambahkan item TTL, dan No. HP pada identitas pasien, pada kolom untuk pengisian No. RM cukup diberikan enam kolom untuk pengisian enam digit nomor rekam medis. Dari segi penutup formulir rekam medis belum sesuai karena komponen utama terakhir formulir berbasis kertas (paper based) adalah 'close' atau penutup dan ini merupakan bagian/ruangan untuk tanda tangan pengontetikasi atau persetujuan.

\section{Mutu Formulir dan Rekam Medis}

Rekam medis yang baik dapat mencerminkan mutu pelayanan kesehatan yang diberikan Rekam medis yang bermutu juga diperlukan untuk persiapan evaluasi dan audit medis tehadap pelayanan medis secara retrospektif terhadap rekam medis (Adhani Windari, A. K. \& L. U, 2015). Tanpa dipenuhinya syarat-syarat mutu dari rekam medis ini, maka tenaga medis maupun pihak rumah sakit akan sulit membela diri di pengadilan bila terdapat tuntutan malpraktik dari pasien (Ajami, S. dan Bagheri Tadi, T, 2013). Mutu rekam medis yang baik adalah rekam medis yang memenuhi indikator- 
indikator mutu rekam medis sebagai berikut (Hertley dan Jones, 2012):

a) Kelengkapan isian resume rekam medis

b) Keakuratan

c) Tepat Waktu

d) Pemenuhan Persyaratan Hukum.

Setiap pelayanan kesehatan memiliki wewenang atau prosedur tetap tersendiri dalam mendesain sebuah formulir namun hal ini harus tetap mengacu pada standar minimal yang harus ada pada setiap formulir (Lemai, Bellucci, E. dan Nguyen, L. T, 2014).

\section{Simpulan dan Saran}

Perlu dilakukan pembaruan desain pada setiap formulir dengan menambahkan tanggal penerbitan yang muncul pada setiap formulir. Hal ini akan dapat membantu menentukan/ memilah formulir yang sedang digunakan tersebut merupakan formulir edisi terbaru, dan membantu dalam pembuangan stok formulir yang sudah tidak terpakai lagi.

\section{Ucapan Terima Kasih}

Terima kasih kami sampaikan kepada pihak-pihak yang membantu pelaksanaan penelitian ini.

\section{Daftar Pustaka}

Adhani Windari, A. K. \& L. U. (2015) “Descriptive Study About The Completeness of Medical Record Documents of Patient."

Ajami, S. dan Bagheri Tadi, T. (2013) “Barriers for Adopting Electronic Health Records (EHRs) by Physicians.," Acta informatica medica : AIM : journal of the Society for Medical Informatics of Bosnia \& Herzegovina: časopis Društva za medicinsku informatiku $\mathrm{BiH}, 21(2)$, hal. 129-34. doi: 10.5455/aim.2013.21.129-134.
Cripps, H. dan Standing, C. (2011) "The Implementation of Electronic Health Records: A Case Study of Bush Computing The Ngaanyatjarra Lands.," International journal of medical informatics. Elsevier Ireland Ltd, 80(12), hal. 841-8. doi: 10.1016/j.ijmedinf.2011.09.007.

Hertley dan Jones (2012) Implementation Electronic Health Record. Second Edi. Amerika: American Medical Association.

Hosizah \& Maryati (2018) Bahan Ajar Rekam Medis \& Informasi Kesehatan - Sistem Informasi Kesehatan II Statistik Pelayanan Kesehatan.

Khalifa, M. (2013) "Barriers to Health Information Systems and Electronic Medical Records Implementation. A Field Study of Saudi Arabian Hospitals," Procedia Computer Science. Elsevier Masson SAS, 21, hal. 335-342. doi: 10.1016/j.procs.2013.09.044.

Lemai, Bellucci, E. dan Nguyen, L. T. (2014) "Electronic Health Records Implementation: An Evaluation of Information System Impact and Contingency Factors," International Journal of Medical Informatics. doi: 10.1016/j.ijmedinf.2014.06.011.

Tierney, M. J. et al. (2013) “Medical education in the electronic medical record (EMR) era: benefits, challenges, and future directions.," Academic medicine : journal of the Association of American Medical Colleges, 88(6), hal. 748-52. doi: 10.1097/ACM.0b013e3182905ceb.

Tola, K. et al. (2017) “Improving Completeness of Inpatient Medical Records in Menelik II Referral Hospital, Addis Ababa, Ethiopia," 2017.

Alamsyah, D. (2011) Manajemen Pelayanan Kesehatan. Yogyakarta: Nuha Medika. 